\title{
Unfolding Process of the Secondary Structure in the Acid Denaturation of Streptomyces Subtilisin Inhibitor
}

\author{
Tomoko KomiYama, Akira Oomori and Makoto MiWA \\ Department of Industrial Chemistry, Seikei University, Musashino, Tokyo 180 \\ (Received August 31, 1984) \\ 小宮山トモ子·大森明·三 輪誠 \\ 成蹊大学工学部工業化学科 武蔵野市吉祥寺北町 ( $\boldsymbol{T} 180)$ \\ (1984年 8 月 31 日受理)
}

\begin{abstract}
Acid denaturation of Streptomyces subtilisin inhibitor was studied with CD and absorption spectroscopies. Difference CD spectra in the far-UV region showed that the $\alpha_{2}$-helix located at the peripheral region unfolds in the first step and the $\beta$-sheet located at the central region unfolds in the second step. The fractional contribution of step I and step II to the total difference CD were $21 \%$ and $79 \%$, respectively. The $\alpha_{2}$-helix is considered to be as the most labile structure in SSI. The complete transformation of local structure around aromatic residues at $\mathrm{pH} 2$ were detected by difference absorption, $\mathrm{CD}$ and fourth-derivative absorption spectra in the near-UV range. An apparent difference in the average number of protons bound per protein molecule during step II was determined to be $3.4 \pm 0.2$.
\end{abstract}

\section{Introduction}

Streptomyces Subtilisin Inhibitor (SSI) is one of Streptomyces origin protease inhibitors. Since the discovery of $\mathrm{SSI}^{1)}$, Alkaline protease inhibitor $^{2)}$, and Plasminostreptin ${ }^{3)}$ have been found as the SSI family inhibitors. These inhibitors are all dimeric and are speculated to have similar secondary structure because of similar sequences of amino acids ${ }^{2,45)}$. Figure 1 shows a schematic drawing of structure of SSI subunit based on X-ray crysrallography ${ }^{6}$. At the first onset of investigation of the structure of these analogous inhibitors, we have studied the denaturation of SSI by absorption and $\mathrm{CD}$ spectroscopic methods. In the previous paper ${ }^{7)}$ we showed that thermal denaturation of SSI is the three-state transition. In thermal denaturation, the first step below $80^{\circ} \mathrm{C}$ is attributable to a partial unfolding of the $\alpha$ - helix portion and the second step between $80^{\circ} \mathrm{C}$ and $94^{\circ} \mathrm{C}$ is attributable to a major unfolding involving the subunit-subunit interface. Acid denaturation of SSI has been investigated by ${ }^{1} \mathrm{H} \quad \mathrm{NMR}^{8)}$ and fluorescence ${ }^{9)}$ spectroscopies. The NMR study has showed that the $\mathrm{C}(2)$ proton of His 106 in the $\alpha_{2}$-helix is protonated between $\mathrm{pH} 7$ and 3.5. The fluorescence study has elucidated that acid denaturation of SSI is the three-state transition by measuring the tryptophan fluorescence. Both studies are confined to the microenvironmental conformation change of probe residues. In this paper, we study acid denaturation of SSI with attempt to obtain global information about unfolding of secondary structure of SSI. Studies on the structure of analogous proteins of SSI family will be presented elsewhere.

The difference CD spectrum in the far-UV range showed that the $\alpha_{2}$-helix portion located 


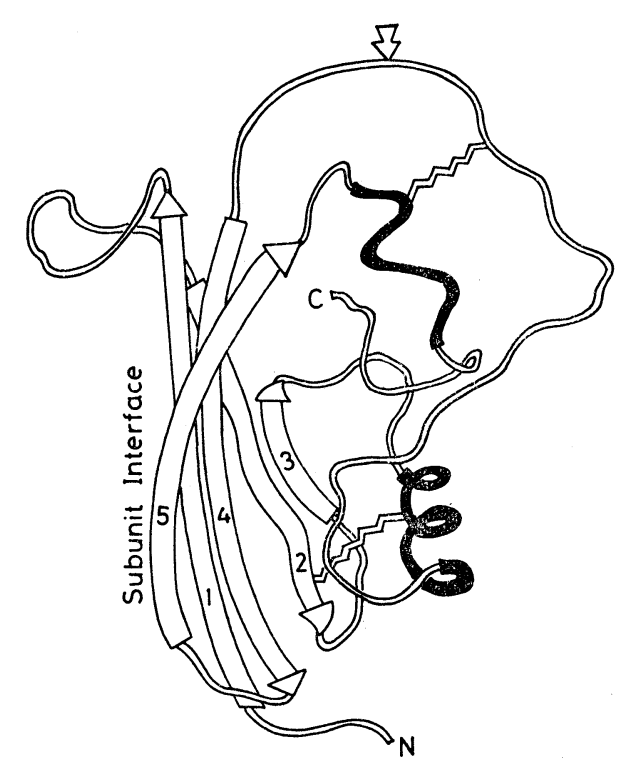

Fig. 1 A schematic drawing of SSI subunit structure. Darkened lines and numbered arrows show $\alpha$-helices and $\beta$ sheet, respectively. Wiggle lines indicate disulfide bonds. An arrow at the top shows the scissile bond (Met 73-Val 74).

at the peripheral region unfolded between pH's 7 and 3.5 to give an intermediate state, preceding the major conformation change of $\beta$ sheet portion located at the central position below $\mathrm{pH}$ 3.5. The transition process of acid denaturation of SSI was found to be similar to that of thermal denaturation. This similarity leads to a conclusion that the $\alpha_{2}$-helix is the most labile structure unit and the $\beta$-sheet is the rigid structure unit of SSI.

The near-UV CD and absorption spectra were measured to detect loosening of local structure around aromatic side chains. Particularly the fourth-derivative spectrum gave characteristic information about the environment around Phe residues.

\section{Experimental Methods}

Crude SSI kindly given by Prof. Murao and his coworkers was purified by their method ${ }^{1}$.

$\mathrm{CD}$ and absorption spectra were measured with a JASCO J-40 AS circular dichroism spectrophotometer and a Hitachi 340 spectrophotometer, respectively. Difference absorption spectra of acid titrated solution were obtained comparing with the absorption spec- trum of the native state. Difference CD spectra were obtained with the data processor by subtracting a $C D$ spectrum from another one.

In measurement of the near-UV spectra concentration of the native SSI was $4.51 \times$ $10^{-5} \mathrm{M}(1.04 \mathrm{mg} / \mathrm{ml})$ in $0.05 \mathrm{M}$ phosphate buffer $(\mathrm{pH} \mathrm{7.0,} \mu=0.1 \mathrm{NaCl})$. We titrated $3 \mathrm{ml}$ of the protein solution in a cell with the optical path of $1 \mathrm{~cm}$ by small aliquots of hydrochloric acid. After addition of acid the solution was gently stirred with a micro-stirrer for ten minutes, then pH's of the solution were measured by inserting a micro-electrode into the solution.

We also detected spectra of Phe residues separately from Tyr and Trp residues by measuring fourth-derivative absorption spectra.

To measure the far-UV spectra concentration of the native SSI was adjusted to be 2.26 $\times 10^{-6} \mathrm{M}$. For the far-UV range, two $\mathrm{ml}$ of the protein solution in a cell with the optical path of $5 \mathrm{~mm}$ was titrated with the acid in a previously described way. One cycle of a measurement at a $\mathrm{pH}$ took one hour. Temperature was kept at $20^{\circ} \mathrm{C}$ by circulating thermostatic water into the holders of optical cells. To examine the irreversibility, the acid denatured solution was neutralized by required amount of sodium hydroxide.

In order to estimate fractional content of each secondary structure, the far-UV CD spectrum was analyzed with the flexible least square method (CONTIN) by Provencher and Glöckner ${ }^{10)}$. Observed molar ellipticity was corrected according to a method previously described $^{7)}$. The secondary structure is classified into three classes of $\alpha$-helix, $\beta$-sheet and remainder ${ }^{10)}$. The class of remainder contains $\beta$-turn, random coil structure and contribution of nonpeptidic chromophores. Application package of CONTIN and user's manual ${ }^{11)}$ are available.

\section{Results}

\subsection{CD and diference absorption spectra in the far-UV range}

Figure $2 \mathrm{a}$ shows the $\mathrm{pH}$ dependence of the far-UV CD spectra during acid titration, Fig. $2 \mathrm{~b}$ the corresponding difference $\mathrm{CD}$ spectra. Analysis of the native $\mathrm{CD}$ spectrum yields $24 \% \alpha$-helix, 36\% $\beta$-sheet and $40 \%$ remain- 


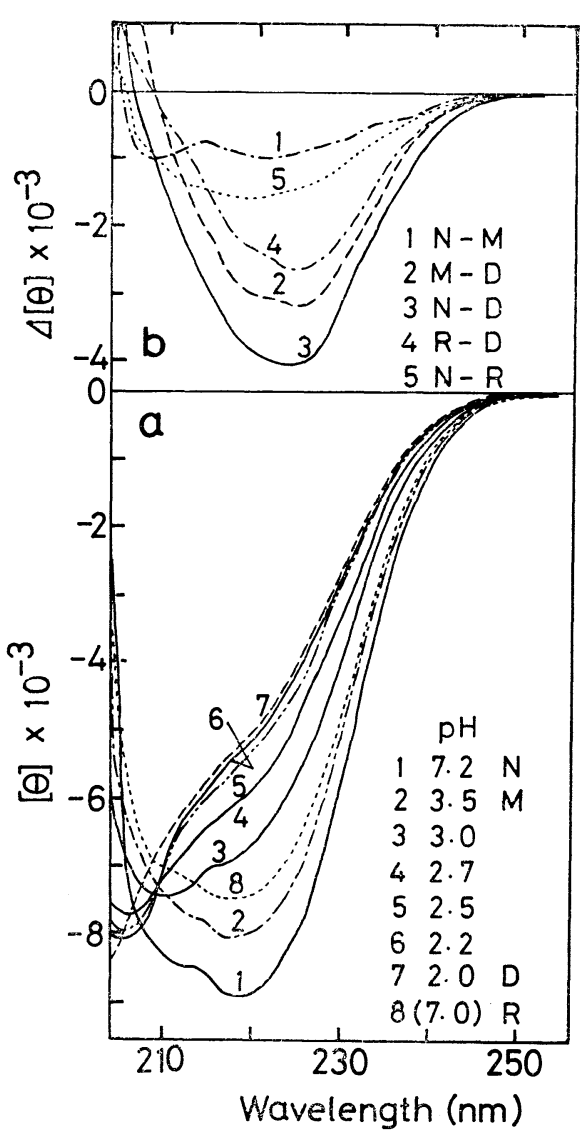

Fig. 2 (a) $\mathrm{pH}$ dependence of the far-UV CD spectra of SSI $\left(0.052 \mathrm{mg} / \mathrm{ml}, 2.26 \times 10^{-6}\right.$ $\mathrm{M}$ in $0.01 \mathrm{M}$ phosphate buffer, $\mu=0.1$ $\mathrm{NaCl}$ ) at room temperature. The optical path was $5 \mathrm{~mm}$. N, M, D and R denote the native, intermediate, denatured and renatured states, respectively. (b) Difference CD spectra of the intermediate, denatured and renatured states measured against the $C D$ of the native state.

der. The present $\mathrm{CD}$ analysis seems to overestimate the content of secondary structure, because the $\mathrm{X}$-ray crystallographic study has given $12 \% \alpha$-helix, $21 \% \beta$-sheet and $67 \%$ random coil structure ${ }^{6)}$. But, we can estimate contents of $\alpha$-helix and $\beta$-sheet to be $15 \%$ and $31 \%$, respectively, by comparing the observed peptide backbone torsion angles ${ }^{12)}$ with the standard angles of respective secondary structures ${ }^{13)}$. The content of $\beta$-sheet based on the main-chain torsion angles agrees with

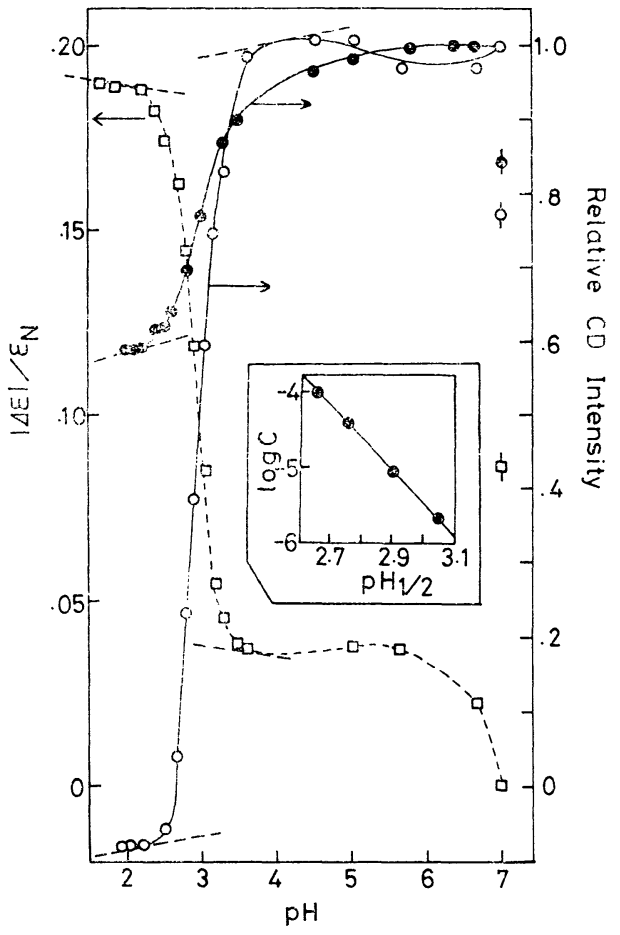

Fig. $3 \mathrm{pH}$ dependence of CD intensity at 218 $\mathrm{nm}$ or $285 \mathrm{~nm}$ and difference absorbance at $292 \mathrm{~nm} 20^{\circ} \mathrm{C}$. Spectral intensities obtained for the renatured state are indicated by the corresponding symbols with a bar. The dashed straight line segments were base lines for the intermediate and the denatured states. Protein concentration were $2.26 \times 10^{-6}$ $\mathrm{M}$ and $4.51 \times 10^{-5} \mathrm{M}$ for measurement in the far-UV and near-UV range, respectively. Inset represents concentration dependence of $\mathrm{pH}_{1 / 2}$ obtained from CD intensity at $218 \mathrm{~nm}$.

- $\mathrm{O}$; relative $\mathrm{CD}$ intensities at 218 $\mathrm{nm}$ and $285 \mathrm{~nm}$

$\square$; difference absorbance at $292 \mathrm{~nm}$ relative to an absorbance of the native state.

that obtained from $\mathrm{CD}$ analysis.

In the $\mathrm{pH}$ range between 7 and $3.5 \mathrm{CD}$ spectra gradually decrease in intensities without any remarkable changes in spectral profile. Below pH 3.5 CD intensities remarkably decrease to give the final ellipticity at $\mathrm{pH} 2.0$. Appearance of an isodichroic point at $210 \mathrm{~nm}$ divides the denaturation process into two parts below and above pH 3.5. Difference CD meas- 


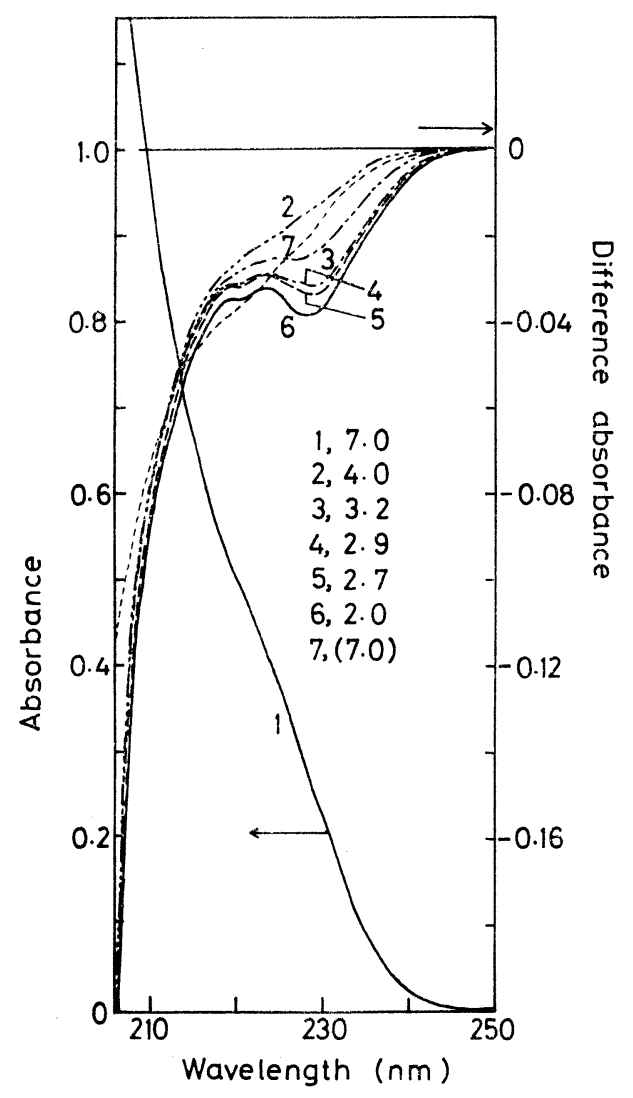

Fig. 4 The far-UV absorption spectrum of the native SSI and difference absorption spectra at various $\mathrm{pH}$ 's against the absorption spectrum of native state.

ured between $\mathrm{pH} 7$ and $\mathrm{pH} 3.5$ shows double minima with weak intensities at $222 \mathrm{~nm}$ and $208 \mathrm{~nm}$ as shown in curve 1 in Fig. 2 b, while difference between $\mathrm{pH} 3.5$ and $\mathrm{pH} 2.0$ shows an intense minimum at $225 \mathrm{~nm}$ and a crossover point at $208 \mathrm{~nm}$ as shown in curve 2 in Fig. 2 b. These two types spectra give evidence for the two distinctive steps, step I and step II, in the conformational change.

A CD of the refolded state (curve 8 in Fig. $2 \mathrm{a}$ ), obtained by standing the solution overnight after neutralization, shows that the protein is approximately refolded with some irreversibility. The reversible component (curve 4 in Fig. 2 b) obtained from the difference CD between the denatured and renatured states possesses $\beta$-like profile, while the irreversible component (curve 5 in Fig. 2 b) obtained from

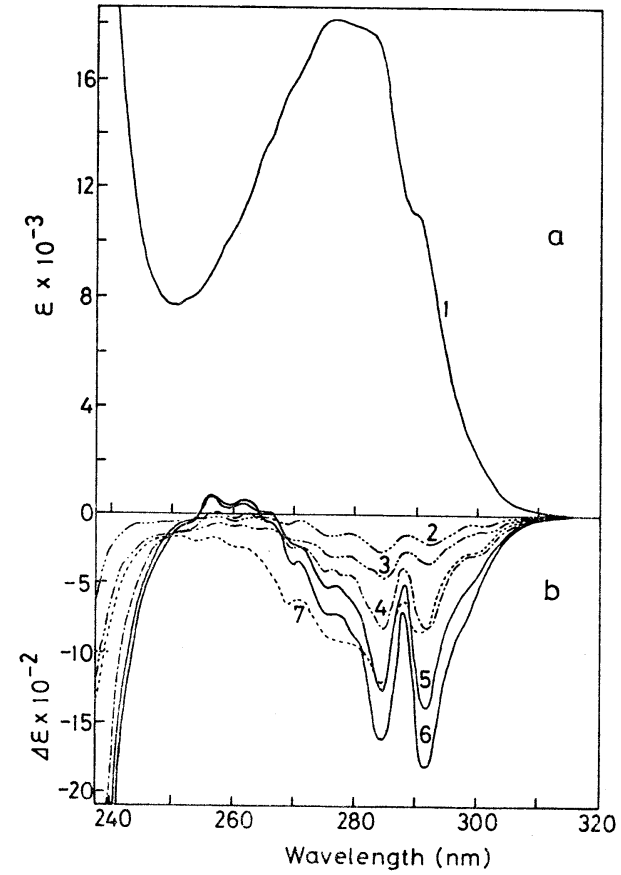

Fig. 5 The near-UV absorption spectrum of the native SSI and difference absorption spectra at various $\mathrm{pH}$ 's against the absorption spectrum of native state. pH's are $1,7.00 ; 2,6.65 ; 3,3.71 ; 4$, $3.05 ; 5,2.80 ; 6,2.20 ; 7,7.00$ (renatured).

the $\mathrm{CD}$ discrepancy between before and after acid denaturation possesses ambiguous profile.

$\mathrm{pH}$ dependence of $\mathrm{CD}$ intensity at $218 \mathrm{~nm}$ shown in Fig. 3 gives 3.05 as a midpoint $\mathrm{pH}$ $\left(\mathrm{pH}_{1 / 2}\right)$ which indicates the half-conversion. The maximum mean residue molar ellipticity at $\mathrm{pH} 2$ was $60 \%$ of the ellipticity at $\mathrm{pH} 7$, indicating that the acid denatured protein has residual structure. The residual intensity disappeared when guanidine hydrochloride or urea was added. Inset of Fig. 3 shows concentration dependence of $\mathrm{pH}_{1 / 2}$ obtained from $\mathrm{CD}$ intensity at $218 \mathrm{~nm}$.

Figure 4 shows denaturation profile of difference absorption spectra in the far-UV range. Above $\mathrm{pH} 3.5$ the difference absorption spectra are diffuse with negative sign, and below $\mathrm{pH} 3.5$ a negative peak appeares at $228 \mathrm{~nm}$. $\mathrm{pH} 3.5$ also separates the process of acid unfolding into two steps, suggesting that the denaturation process detected by difference ab- 
sorption is identical with that by the difference $C D$.

\subsection{Spectral changes in the near-UV range}

The concentration of the protein solution which was used for spectral measurements in the near-UV range was twenty times as high as the concentration of the protein solution used in the far-UV range. Hence the solution became considerably turbid at the $\mathrm{pH}$ range close to pI of SSI $(4.3)^{14)}$, we measured spectra at rough intervals in this $\mathrm{pH}$ range.

Figure $5 \mathrm{~b}$ shows the near-UV difference $a b$ sorption spectra at various pH's. At $\mathrm{pH} 2.2$ the difference spectrum (curve 6) has two negative peaks at $285 \mathrm{~nm}$ and $292 \mathrm{~nm}$, and negative shoulders at $269 \mathrm{~nm}, 275 \mathrm{~nm}$ and 297 $\mathrm{nm}$, and positive fine structures in the range between $250 \mathrm{~nm}$ and $270 \mathrm{~nm}$. A peak at 292 $\mathrm{nm}$ is mainly attributable to a Trp residue and a peak at $285 \mathrm{~nm}$ to Trp and Tyr residues because these wavelengths coincide with those for Gly-L-Trp-Gly and Gly-L-Tyr-Gly. Weak positive difference bands centered at $260 \mathrm{~nm}$ are attributable to Phe residues because of the

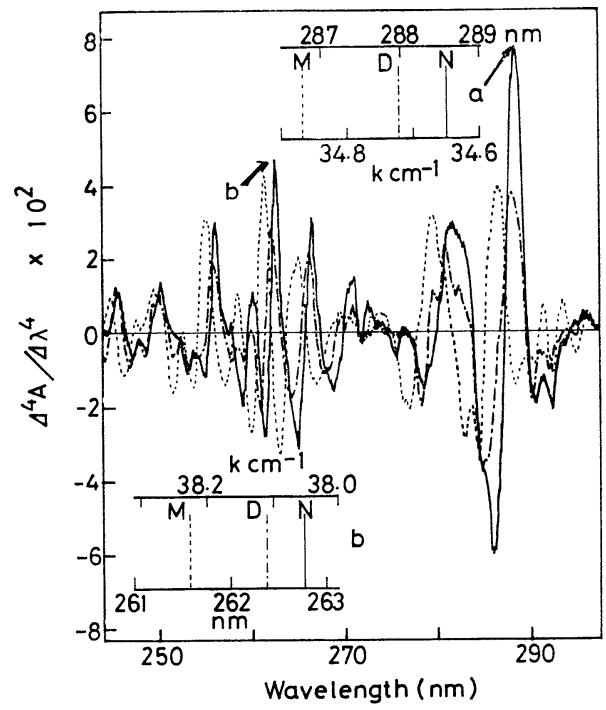

Fig. 6 The fourth-derivative absorption spectra of the native (-) and denatured (-.-) SSI, and the spectrum of the model system (....). Inset $a$ and $b$ represent the position of peaks due to Trp and Phe residues, respectively. $\mathrm{N}, \mathrm{D}$ and $\mathrm{M}$ denote the native, denatured SSI and the model system, respectively. vibrational fine structure. We showed $\mathrm{pH}$ dependence of relative difference absorbance at $292 \mathrm{~nm}$ in Fig. 3.

The fourth derivative absorption spectra were measured for the native and the acid denatured solution as shown in Fig. 6. The spectrum obviously indicates the denaturation blue shift of peaks due to Phe residues which had not been separately detected. Equally spaced peaks of derivative spectra centered at $260 \mathrm{~nm}$ can be associated with vibrational structures of the phenyl group and these peaks are assignable to Phe residues. Acid unfolding causes peaks of derivative spectra to shift to shorter wavelengths $\left(60-70 \mathrm{~cm}^{-1}\right)$ as shown in insets $a$ and $b$ of Fig. 6 .

Figure 7 shows an effect of acid on the near-UV CD spectrum. In the $\mathrm{pH}$ range between 7 and 3.5, a minor change appeared in $\mathrm{CD}$ intensity. Tendency of the near-UV CD intensities (empty circles in Fig. 3) to increase in the $\mathrm{pH}$ range close to $\mathrm{pI}$ is a superficial change which is attributable to turbidity of the solution. Below pH 3.6 CD intensities de-

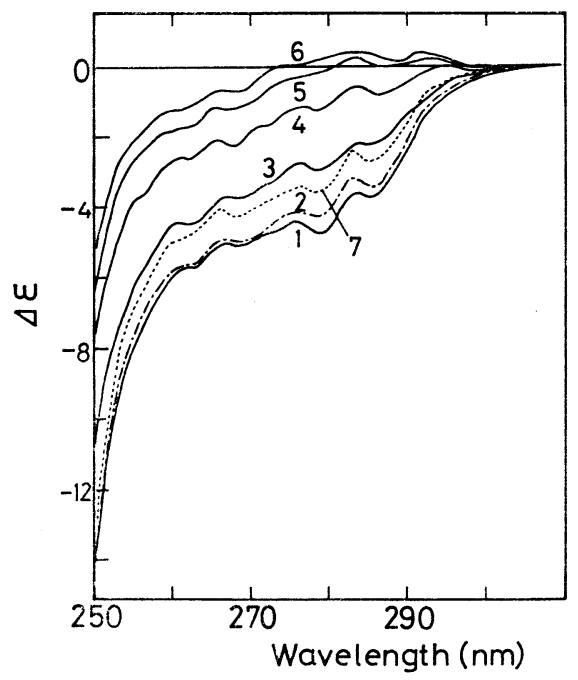

Fig. 7 The near-UV CD spectra of SSI at various pH's. The optical path was $1 \mathrm{~cm}$. Protein concentration was 5.22 $\times 10^{-5} \mathrm{M}(1.2 \mathrm{mg} / \mathrm{ml})$ in $0.01 \mathrm{M}$ phosphate buffer $(\mu=0.1 \mathrm{NaCl})$.

pH's are $1,7.20 ; 2,3.60 ; 3,3.10 ; 4$, $2.80 ; 5,2.50 ; 6,2.20 ; 7,7.0$ (renatured). 
creased with decreasing pH. As shown in Figs. 3 and 6 the local environment around aromatic residues almost completely melts down at the endpoint of acid titration, contrary to the case of secondary structure as previously described.

\section{Discussion}

We can now represent acid denaturation of SSI by the following equation:

$$
\begin{gathered}
\mathrm{N} \longrightarrow \mathrm{M} \longrightarrow \mathrm{D} \\
\text { step I step II }
\end{gathered}
$$$$
\mathrm{pH} 7.0 \quad 3.5 \quad 2.0
$$

where $\mathrm{N}, \mathrm{M}$ and $\mathrm{D}$ indicates the native state, the intermediate and the denatured states of SSI, respectively. Appearance of the isodichroic point at $210 \mathrm{~nm}$ shows the beginning of the major denaturation process (step II). The relative ellipticity at $218 \mathrm{~nm}$ shows that the fractional contribution of step I and step II to the total difference CD were $21 \%$ and $79 \%$, respectively. These extents of denaturation agree with those obtained from a fluorescence study $^{92}$.

The intermediate state gives a difference CD with two minima (curve 1 in Fig. 2), indicating that unfolding occurs at the $\alpha$-helix portion. Denatured fraction of the $\alpha$-helix at pH 3.5 is calculated to be about $3 \%$ of the whole molecule with a library value for the ellipticity of $\alpha$-helix at $222 \mathrm{~nm}^{15)}$, if we simply assume that the total change in step I arises from the $\alpha$-helix. It amounts to about one eighth of $\alpha$-helix content of the native state. Step I seems to be a partial unfolding of the $\alpha$-helix. X-ray study has clarified that $\alpha_{2}-$ helix is loose $^{6)}$. Since two $\alpha$-helices of SSI contain no spectroscopic probes like Phe, Tyr and Trp residues, we attempted to show the correlation map of the water affinity of SSI amino acid side chains (Fig. 8). Ordinate of Fig. 8 is the hydration potentials of amino acid side chains determined by Wolfenden et $a l^{16)}$. Side chains of $\alpha_{2}$-helix components represent the much higher water affinity than those of $\alpha_{1}$-helix components. Moreover, ${ }^{1} \mathrm{H}$ NMR study has clarified that $\mathrm{C}(2)$ proton of His 106 is protonated in this $\mathrm{pH}$ range $\mathrm{e}^{8)}$. Based on these facts, we conclude that $\alpha_{2}$-helix unfolds in this $\mathrm{pH}$ range.

Slight changes in the near-UV absorption

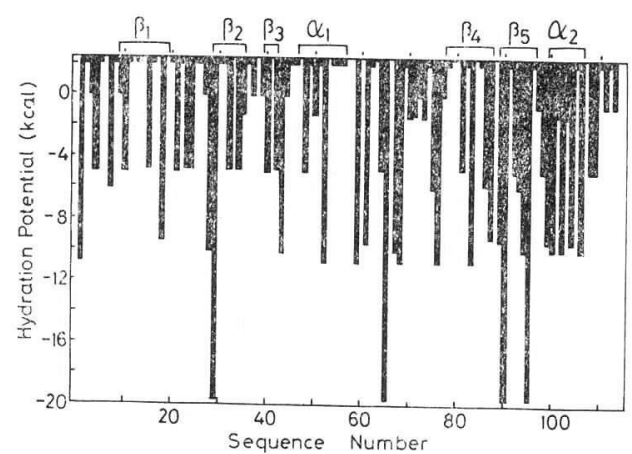

Fig. 8 A map of relative hydration potentials of amino acid side chains of SSI subunit. The hydration potentials were taken from ref. 16. The extremely long bars mark the hydrophilic side chain of Arg. Segments of $\alpha$-helices and $\beta$-strands defined by the X-ray study ${ }^{()}$are indicated in the upper part of the map.

(Figs. 3 and 5) and CD (Figs. 3 and 7) spectra during step I indicate a little change around aromatic residues located near the helix. CD studies in the far-and near-UV region, coupled with the 'H NMR study, suggest that step $I$ is unfolding of $\alpha_{2}$-helix and consequently loosening near it. This clearly shows that the helix is the most labile structure unit in SSI.

On the other hand, step II gives an intense difference $C D$ of which peak is at $225 \mathrm{~nm}$ and crossover point at $208 \mathrm{~nm}$, indicating that this step occurs mainly at the $\beta$-sheet portion. If total CD change in step II arises from unfolding of the $\beta$-sheet, denatured fraction of $\beta$ sheet at $\mathrm{pH} 2.0$ amounts to $23 \%$ of the whole residues of SSI, applying a library value for the ellipticity of the structure ${ }^{17}$. This amount corresponds to about $64 \%$ of $\beta$-sheet content of the native inhibitor, indicating that significant part of the $\beta$-sheet unfolds. The isodichroic point at $210 \mathrm{~nm}$ suggests conversion of $\beta$-sheet into random coil structure. Figure 4 shows that the difference absorption with a peak at $228 \mathrm{~nm}$ is mainly attributable to unfolding of $\beta$-sheet. A spectroscopic study by Rosenheck and Doty ${ }^{18)}$ supports this interpretation. They demonstrated that the molar extinction coefficient of $\beta$-sheet structure is larger than those of $\alpha$-helix and random coil structure in this wavelength range. 
Figs. 3 and 7 show that the local structure around aromatic sites completely transforms in the denatured state of SSI. Buried aromatic residues monitored by the present spectroscopies are Trp 86, Tyr 93 and Phe 97, 111 and 113 residues. Since the Trp and Tyr residues are contained in $\beta_{4}$ and $\beta_{5}$ strands, respectively, these spectral changes indicate unfolding of these $\beta$-strands. Fujii et al. have found with the ${ }^{1} \mathrm{H}$ NMR study ${ }^{8}$ that the protonation of His 43 , which is deeply buried in the hydrophobic core and adjacent to the $\beta_{3}$ strand, occurs at an identical $\mathrm{pH}$ range with that observed for the present study. Local transition around $\operatorname{Trp} 86$ in $\beta_{4}$-strand has been detected by fluorescence change during acid denaturation $^{9)}$. Step II, thus, is the conformational transition including the entire molecule. Difference CD between the renatured and denatured states (curve 4 in Fig. 2 b) is similar in profile to that between the intermediate and denatured states (curve 2 in Fig. 2 b), implying that step II of acid denaturation of SSI is satisfactorily reversible unfolding.

Properties of SSI acid denaturation are summarized as follows; i) the two-step unfolding characterized by the preceding step mainly at the $\alpha_{2}$-helix portion and the successive step mainly at the $\beta$-sheet portion, ii) appearance isodichroic point in denaturation profile of the faru-UV CD spectra in step II, and iii) the residual structure at the denatured state. All these properties agree with those found for thermal denaturation ${ }^{7)}$. Change from step I to step II takes place at $80^{\circ} \mathrm{C}$ in thermal denaturation, corresponding to the $\mathrm{pH}$ of 3.5 in the present acid denaturation. $\mathrm{CD}$ in the second step of thermal denaturation showed an isodichroic point at about $210 \mathrm{~nm}$. Close analogy found between acid and thermal denaturation suggests that decreasing $\mathrm{pH}$ below 2 and heating above $90^{\circ} \mathrm{C}$ give similar effect on the secondary structure of the protein. SSI subunit contains 12 carboxyl groups (6 from Asp, 5 from Glu, and 1 from the C-terminal Phe). Two Glu residues are members of $\alpha_{2}$-helix. One Asp belongs to $\alpha_{1}$-helix and two Asp to $\beta_{4}$ strand. Protonation of these residues would lead to global unfolding of secondary structure and give similar denaturation profile of electronic spectra to that obtained from thermal denaturation.

We analysed acid denaturation of SSI by assuming the dissociative process supported with concentration dependence of the midpoint $\mathrm{pH}$ shown in Fig. 3 inset. $\mathrm{D}$ in equation (1) needs to be replaced by $2 \mathrm{D}$ as follows;

$$
\begin{aligned}
& \mathrm{N} \longrightarrow \mathrm{M} \longrightarrow 2 \mathrm{D} \\
& \alpha_{1} \alpha_{2, \hat{j}} \quad \alpha_{1,} \hat{j} \quad \mathrm{r}
\end{aligned}
$$

where $\mathrm{r}$ indicates the residual structure at $\mathrm{pH}$ 2. $\mathrm{pH}$ dependence of step II is conventionally analysed in terms of $\Delta \mathrm{n}^{19)}$, the apparent difference in the number of protons bound per protein molecule, as follows;

$$
\mathrm{In}=\frac{\mathrm{d} \ln \mathrm{K}}{\mathrm{d} \ln \left[\mathrm{H}^{+}\right]}=\frac{\mathrm{d} \ln \left(\left(4 \mathrm{f}^{2} / 1-\mathrm{f}\right) \mathrm{C}_{0}\right)}{\mathrm{d} \ln \left[\mathrm{H}^{+}\right]} \text {(3), }
$$

where $\mathrm{K}, \mathrm{f}$ and $\mathrm{C}_{0}$ is the apparent equilibrium constant, denatured fraction and the initial concentration in dimer basis, respectively. In was estimated to $3.4 \pm 0.2$ from a linear relation between $\mathrm{pH}$ and $\log \mathrm{K}$ shown in Fig. 9,

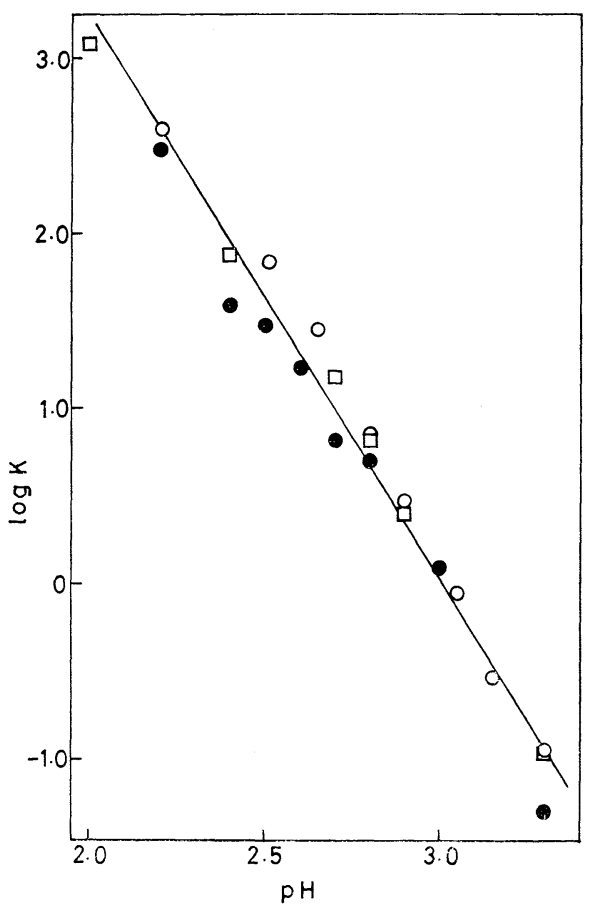

Fig. $9 \mathrm{pH}$ dependence of $\log \mathrm{K}$ obtained from $\mathrm{CD}$ intensities at $218 \mathrm{~nm}$ ( and 285 $\mathrm{nm}(\mathrm{O})$, and difference absorbances at $292 \mathrm{~nm}(\square)$ during the major denaturation process. Values of $\log \mathrm{K}$ were calculated on assumption that SSI undergoes a dissociative transition. 
indicating that the major unfolding is a cooperative transition.

In summary, the $\alpha_{2}$-helix is the labile element of the SSI structure, while the $\alpha_{1}$-helix constitutes the rigid hydrophobic core. A disulfide bond links Cys 101 in the $\alpha_{2}$-helix to Cys 71 in the flexible outer arm of SSI (Fig. 1). The $\alpha_{2}$-helix would support the loop formed with Cys 71-101 disulfide bond with flexibility. In this loop the active site (Met 73-Val 74) of SSI is located (Fig. 1). Thus, the helix is speculated to play an important role when SSI reacts as inhibitor. Our CD studies show that a same speculation would hold for a moderated SSI, the active site peptide bond of which is cleaved with subtilisin BPN' (our unpublished result). But, it should be noted that the hydrophobic core supported by the central $\beta$ sheet possesses an extreme rigidity indispensable to the protease inhibitor.

\section{References}

1) S. Murao, and S. Sato: Agric. Biol. Chem. 37, 1067 (1973).

2) M. Ueda, K. Suzuki, and M. Shibata: Agr. Biol. Chem., 40, 1479 (1976).

3) A. Kakinuma, H. Sugino, N. Moriya, and M. Isono: J. Biol. Chem. 253, 1529 (1978).

4) T. Ikenaka, S. Odani, M. Sakai, Y. Nabeshima, S. Sato, and S. Murao: J. Biochem. 76, 1191
(1974).

5) H. Sugino, A. Kakinuma, and S. Iwanaga : J. Biol. Chem. 253, 1546 (1978).

6) Y. Mitsui, Y. Satow, Y. Watanabe, and Y. Iitaka: J. Mol. Biol. 131, 697 (1979).

7) T. Komiyama, M. Miwa, T. Yatabe, and $H$. Ikeda: J. Biochem. 95, 1569 (1984).

8) S. Fujii, K. Akasaka, and H. Hatano: J. Biochem. 88, 789 (1980).

9) Y. Uehara, B. Tonomura, and K. Hiromi: J. Biochem. 94, 903 (1983).

10) S. W. Provencher, and J. Glöckner: Biochemistry, 20, 33 (1981).

11) S. W. Provencher: Technical Report (European Molecular Biology Laboratory) DA05, (Heiderberg, 1982).

12) Y. Mitsui: Private communication.

13) IUPAC-IUB Commission of Biochemical Nomenclature: J. Mol. Biol. 52, 1 (1970).

14) S. Sato, and S. Murao: Agric. Biol. Chem. 38, 587 (1974).

15) Y. Chen, T. T. Yang, and K. H. Chau: Biochemistry, 13, 3350 (1974).

16) R. Wolfenden, L. Anderson, P. M. Cullis, and B. B. Southgate: Biochemistry, 20, 849 (1981).

17) S. Brahms and J. Brahms: J. Mol. Biol. 183, 149 (1980).

18) K. Rosenheck, and P. Doty: Proc. Nat. Am. Soc. 47, 1775 (1961).

19) S. Lapanje: Physicochemical Aspects of Protein Denaturation (John Wiley \& Sons, Inc., New York, 1978) p. 269 